\title{
Double blind clinical and laboratory study of hypoglycaemia with human and porcine insulin in diabetic patients reporting hypoglycaemia unawareness after transferring to human insulin
}

\author{
Alberto Maran, Jill Lomas, Helen Archibald, Ian A Macdonald, Edwin A M Gale, Stephanie A Amiel
}

\begin{abstract}
Objectives-To compare awareness of hypoglycaemia and physiological responses to hypoglycaemia with human and porcine insulin in diabetic patients who reported loss of hypoglycaemia awareness after transferring to human insulin.

Design-Double blind randomised crossover study of clinical experience and physiological responses during slow fall hypoglycaemic clamping with porcine and human insulin.
\end{abstract}

Setting-Clinical investigation unit of teaching hospital recruiting from diabetes clinics of five teaching hospitals and one district general hospital.

Subjects -17 patients with insulin dependent diabetes mellitus of more than five years' duration who had reported altered hypoglycaemia awareness within three months of transferring to human insulin.

Main outcome measures-Glycaemic control and frequency of hypoglycaemic episodes during two months' treatment with each insulin. Glucose thresholds for physiological and symptomatic responses during clamping.

Results-Glycaemic control did not change with either insulin. 136 hypoglycaemic episodes (eight severe) were reported with human insulin and 149 (nine severe) with porcine insulin $(95 \%$ confidence interval -4 to $2 \cdot 5, p=0.63$ ). 20 episodes of biochemical hypoglycaemia occurred with human insulin versus 18 with porcine insulin $(-0.8$ to 1 , $\mathbf{p}=\mathbf{0} \cdot \mathbf{7 8}$ ). During controlled hypoglycaemia the mean adrenaline response was $138 \mathrm{nmol} / 240 \mathrm{~min}$ for both insulins; neurohormonal responses were triggered at 3.0 (SE 0.2$)$ versus $3.1(0.2) \mathrm{mmol} / \mathrm{l}$ of glucose for adrenaline and $2.5(0.1)$ versus $2.5(0.1) \mathrm{mmol} / \mathrm{h}$ for subjective awareness.

Conclusions-These data suggest that human insulin per se does not affect the presentation of hypoglycaemia or the neurohumoral, symptomatic, and cognitive function responses to hypoglycaemia in insulin dependent diabetic patients with a history of hypoglycaemia unawareness.

\section{Introduction}

There has been considerable public concern about reduced hypoglycaemia awareness in patients taking human insulin. Impaired awareness of warning symptoms in patients transferred from animal insulins has been reported, ${ }^{1-3}$ risking increased frequency of severe hypoglycaemia. Although most studies have reported that the incidence of severe hypoglycaemia is not affected by introducing human insulin, ${ }^{4-9}$ the Swiss group which first described problems with human insulin has published two further studies which seem to support their initial contention. ${ }^{10} 11$

The mechanisms underlying loss of awareness of hypoglycaemia have been extensively investigated.
Impairment of neurohumoral responses to experimentally induced hypoglycaemia has been shown in two groups of patients - those with a history of recurrent severe hypoglycaemia and those receiving intensified insulin therapy. ${ }^{12-16}$ Most comparisons between human and animal insulins have been based on responses to acute hypoglycaemia, often in nondiabetic subjects, and have found little $\mathrm{e}^{17-22}$ or $\mathrm{no}^{23-27}$ difference between responses with the different species of insulins. A recent study on patients who were selected because of changes in warning symptoms associated with the change of insulin species found no differences between responses to hypoglycaemia induced by porcine or human insulin. ${ }^{28}$ This report was criticised because of the small number of patients studied and because patients had not been stabilised on each insulin before acute hypoglycaemia was induced. ${ }^{29}$ We conducted a crossover double blind study in a larger sample of patients with altered perception of hypoglycaemia after changing to human insulin. Patients were established on porcine and human insulin before experimental hypoglycaemia was induced.

\section{Subjects and methods}

We recruited subjects from the diabetes clinics of five teaching hospitals and one district general hospital. The clinic physicians were asked to refer any patient with insulin dependent diabetes mellitus who had experienced either severe hypoglycaemia without warning or who relied on others to detect their hypoglycaemia after transferring to human insulin. We contacted patients for a preliminary interview to assess their history and if they met the study criteria they were invited to join the study. Patients had to have had insulin treated diabetes mellitus for more than five years and a history of altered awareness of hypoglycaemia within three months of transferring to human insulin. Patients with ischaemic heart disease, epilepsy or non-hypoglycaemia related seizure disorder, uncontrolled hypertension, or unstable proliferative retinopathy, and those taking drugs that might interfere with autonomic or cognitive function or their ability to complete the study were excluded.

We used the threshold glucose concentration for counterregulation as the main parameter to calculate sample size. The intrapatient standard deviation for this parameter was assumed to be $0.6 \mathrm{mmol} / \mathrm{l}$. To detect a difference of $0.6 \mathrm{mmol} / 17$ patients would be required for $80 \%$ power at the $5 \%$ significance level. ${ }^{15} 30$

Thirty two patients volunteered for the study, of whom eight were unsuitable for study (because of untreated hypothyroidism, erratic diet and exercise, depression, a renal transplant, taking anticoagulants, taking benzodiazepines (two), insufficient time). Two additional patients seen by the recruiting centre 
refused to participate because they had restarted treatment with animal insulin and would not take human insulin again. Of the 24 patients who fulfilled the entry criteria, six were unable to comply with the exigencies of the protocol and did not complete the run in period and one patient was later found to be misusing drugs and her data were not included in the analysis. Thus 17 (five women) patients completed the study. The mean (SD) age of the study group was 36 (11) years) and mean duration of diabetes 18 (7.9) years. Six patients had asymptomatic autonomic neuropathy with a $R-R$ interval variation of less than 10 beats per minute without postural hypotension and four had background retinopathy. Two patients were taking antihypertensive drugs (one captopril and frusemide and the other methyldopa), one of whom had impaired renal function and had required laser therapy for retinopathy.

Each subject was studied for six months. Throughout the study subjects were asked to complete at least one seven point home blood glucose monitoring profile a week and to collect a series of capillary blood samples simultaneously with the home monitoring profile at least once a fortnight. Subjects were asked to complete a simple questionnaire every time they experienced hypoglycaemia. The questionnaire used the term "mild" to describe all self treated episodes and "severe" to describe all episodes where help was needed from a second person. Data were recorded at clinic visits every two weeks, at which time blood was taken for measurement of fructosamine concentrations. Insulin doses were not altered throughout the study except to ensure (on the basis of the home blood glucose test results) that glycaemic control was not altered or to avoid unacceptable hypoglycaemia (mainly during the run in phase).

The first two months was a run in phase during which patients remained on their usual insulin. After this, subjects were allocated to treatment with each insulin species (pyr human insulin (human Actrapid and Protaphane, Novo Nordisk, Copenhagen, Denmark) or porcine insulin (Actrapid and Insulatard, Novo Nordisk), for two months in random order. Randomisation was blocked so that the two possible sequences (pork/human, human/pork) were evenly distributed among subjects. Investigators and subjects were blinded to insulin type and the insulins were given in random order.

At enrolment and at the end of each treatment period, subjects and their closest relative or friend completed a questionnaire about symptoms and signs during hypoglycaemia. At the end of each treatment period each subject's responses to hypoglycaemia were formally tested by a slow fall hypoglycaemic clamp with soluble insulin of the species the subject was currently taking.

The slow fall clamp technique has been described previously. ${ }^{30}$ In brief, subjects were admitted to the metabolic unit on the evening before study and overnight glucose control was achieved by monitored intravenous insulin infusion. Subjects fasted from midnight and in the morning a primed continuous intravenous infusion of soluble insulin (in a $4 \%$ solution of the subject's blood in $0.9 \%$ saline) was started, with a maintenance rate of $1.5 \mathrm{mU} / \mathrm{kg} / \mathrm{min}$. Blood glucose concentration was held at $5 \mathrm{mmol} / \mathrm{h}$ for 40 minutes by simultaneous infusion of $20 \%$ glucose (Baxter Health Care, Thetford, Norfolk) and then reduced stepwise over the next 220 minutes to a low of $2 \mathrm{mmol} / \mathrm{l}$; the concentration was then restored to $5 \mathrm{mmol} / \mathrm{l}$ and held there until 260 minutes. Arterialised venous blood (from a retrograde distal intravenous cannula with a hot air box to warm the hand ${ }^{31}$ ) was sampled throughout for glucose, insulin, and counterregulatory hormones. Subjective awareness was assessed by a questionnaire listing 52 symptoms (including dummies unrelated to hypoglycaemia) which the patient ranked on a linear analogue scale from 0 (none) to 6 (very severe). ${ }^{32}$ Symptom scores were calculated from tire questionnaires as the increase over the baseline score for autonomic symptoms (sweating, heart pounding, warmness, anxiety, tingling, and trembling), neuroglycopenic symptoms (inability to concentrate, confusion, drowsiness, tiredness, dizziness, weakness, blurred vision, and irritability), and total symptoms (autonomic plus neuroglycopenic score). Cerebral function was tested by measuring four choice reaction times twice at each glucose plateau. ${ }^{33}$ Reaction times were recorded five times at euglycaemia before starting to eliminate a learning effect.

The study was approved by the ethics committee of the United Medical and Dental Schools of Guy's and St Thomas's Hospitals. Written informed consent was obtained from each patient before enrolment.

\section{MEASUREMENTS AND CALCULATIONS}

Plasma glucose (during clinical monitoring) and blood glucose (during the clamps) concentrations were measured by a glucose oxidase method (Yellow Springs glucose analyser, Yellow Springs Instrument, Ohio, United States). Catecholamine concentrations were measured by high pressure liquid chromatography, ${ }^{33}$ and cortisol, glucagon, growth hormone, and free insulin concentrations by radioimmunoassays. ${ }^{34}$ Paired studies were measured in the same assay runs. Intraassay variation for any assay was less than $10 \%$.

Demographic data are presented as mean (SD); elsewhere data are quoted as mean (SE) unless otherwise stated. Observations during two months' treatment with porcine insulin were compared with observations during treatment with human insulin, by the paired Student's $t$ test. This test was also used to compare total hormonal responses to human and porcine insulin in the clamp studies. During clamps a significant rise in plasma hormone concentration was defined as a concentration greater than the mean of the five baseline (euglycaemic) values plus two standard deviations in two or more consecutive samples. For symptom scores a significant increase was defined as a rise in score of two points or more over the score at euglycaemia, again for two or more consecutive readings. A significant deterioration in cognitive function was defined as two or more consecutive increments of $5 \%$ or more in the mean time taken for a correct response and of $2 \%$ or more in the error rate with the last of the five euglycaemic test scores used as baseline. The glucose concentration at the time of onset of a significant change in each parameter was identified for each subject and data were compared by paired Student's $t$ test or Wilcoxon signed rank tests, as appropriate. When a subject did not show a significant change during the clamp test, a glucose concentration of $2 \mathrm{mmol} / \mathrm{l}$ was assigned for statistical comparisons of glucose thresholds.

Data were analysed with the statistical program SPSS, version 4.0 (SPSS, Chicago, Illinois, United States). p Values less than 0.05 were considered significant.

\section{Results}

\section{CLINICAL PERIOD}

The mean (SE) fructosamine concentration was the same $(2.8(0 \cdot 1) \mathrm{mmol} / \mathrm{l})$ after two months' treatment with human and porcine insulin. The mean insulin dose was 51(5) U/day for both insulins. Subjects reported 153 episodes of hypoglycaemia during the run in phase (taking their usual insulin), 136 hypoglycaemic episodes $(8(1.8)$ per patient) while taking human 
insulin, and 149 episodes $(8 \cdot 8(2 \cdot 2))$ while taking porcine insulin $(95 \%$ confidence interval -4 to $2 \cdot 5$; $\mathrm{p}=0.63) ; 10$, eight, and nine episodes respectively were severe. The seven point 24 hour blood glucose profiles showed $25(1.4(0.3)$ per patient) episodes of biochemical hypoglycaemia (blood glucose $<2.8 \mathrm{mmol} / \mathrm{l})$ during the run in period, $20(1.2(0.3))$ with human insulin, and $18(1.1(0.2))$ with porcine insulin $(-0.8$ to $1 ; p=0.78)$. As doses were not adjusted when changing insulin species we also examined the frequency of hypoglycaemic episodes in the first two weeks after each conversion. This showed 46 episodes $(2.7(0.6)$ per patient), of which 41 were mild, on transferring to human insulin versus 29 episodes $(1.7(0.6))$, of which 26 were mild, on transferring to porcine insulin $(-0 \cdot 1$ to $2 ; p=0 \cdot 08)$. No significant differences were found in the frequency of hypoglycaemia during the last six weeks of each treatment period $(90(5 \cdot 3(1.4)$ per patient) with human insulin $v 120(7 \cdot 1(1.9))$ with porcine insulin $(-4.5$ to $1 \cdot 2 ; \mathrm{p}=0 \cdot 22)$ ).

After two months' treatment with human insulin five subjects described increased symptoms during clinical hypoglycaemia (three autonomic, one neuroglycopenic, and one both) while two reported reduced symptoms. Five reported increased symptoms while taking porcine insuline (three autonomic, one neuroglycopenic, and one both). There were no significant differences between the total, autonomic, and neuroglycopenic scores reported by subjects to be important to them at the beginning of a hypoglycaemic attack or later during its progression. Table I shows the scores for all symptoms included in the end of treatment questionnaire. Nor did the questionnaires completed by patients' relatives show any differences in the signs of hypoglycaemia with either insulin (median (range) score for signs at onset of hypoglycaemia 34 (4-48) for human insulin $v 32.5(5-45)$ for porcine; $95 \%$ confidence interval -5 to $15, Z=0 \cdot 3$, $p=0 \cdot 79$ ). Nine patients correctly identified the species of insulin they were receiving, six were wrong, and two did not know. The data on the nine subjects who correctly identified each insulin were analysed separately but the results were not different from those of the whole group.

TABLE I-Median (range) symptom scores for hypoglycaemic episodes during two months' treatment with human and porcine insulin

\begin{tabular}{|c|c|c|c|c|}
\hline & Human & Porcine & $Z$ & p Value ${ }^{\star}$ \\
\hline \multicolumn{5}{|l|}{ At onset of attacks: } \\
\hline Total & $12(1-58)$ & $21(4-42)$ & $-1 \cdot 17$ & $0 \cdot 24$ \\
\hline Autonomic & $6(0-26)$ & $9(1-14)$ & -1.65 & $0 \cdot 1$ \\
\hline Neuroglycopenic & $9(0-32)$ & $13(3-30)$ & $-0 \cdot 80$ & 0.42 \\
\hline \multicolumn{5}{|c|}{ During hypoglycaemia: } \\
\hline Total & $24(13-46)$ & $28(7-47)$ & $-0 \cdot 45$ & 0.66 \\
\hline Autonomic & $9(3-16)$ & $10(2-16)$ & -0.49 & 0.62 \\
\hline Neuroglycopenic & $12(5-30)$ & $12(5-33)$ & $-0 \cdot 25$ & 0.8 \\
\hline \multicolumn{5}{|c|}{ During worst attack in last 8 weeks: } \\
\hline Total & $19(0-75)$ & $19(8-49)$ & $-0 \cdot 35$ & 0.72 \\
\hline Autonomic & $4(0-34)$ & $6(0-21)$ & $-0 \cdot 70$ & 0.48 \\
\hline Neuroglycopenic & $10(0-41)$ & $14(0-33)$ & $-0 \cdot 14$ & 0.89 \\
\hline
\end{tabular}

*Wilcoxon signed rank test.

TABLE II-Neurohumoral and symptomatic responses during hypoglycaemic clamps with porcine and human insulin

\begin{tabular}{|c|c|c|c|c|}
\hline & Human & Porcine & $\begin{array}{l}\text { 95\% Confidence interval for } \\
\text { difference of means }\end{array}$ & p Value ${ }^{\star}$ \\
\hline \multicolumn{5}{|l|}{ Mean (SE) size of response: } \\
\hline Adrenaline $(\mathrm{nmol} / / 240 \mathrm{~min})$ & $138 \cdot 2(25)$ & $138 \cdot 3(21)$ & -51 to 51 & 0.99 \\
\hline Noradrenaline (nmol//240 min) & $298(38)$ & $307 \cdot 5(30)$ & -70 to 51 & 0.85 \\
\hline Growth hormone (mU//240 $\mathrm{min})$ & $3442 \cdot 3(531)$ & $3404 \cdot 8(474)$ & -708 to 783 & 0.96 \\
\hline \multicolumn{5}{|c|}{$\begin{array}{l}\text { Mean (SE) glucose threshold for response } \\
\text { (mmol/l): }\end{array}$} \\
\hline Adrenaline & $3.0(0 \cdot 2)$ & $3 \cdot 1(0 \cdot 2)$ & -0.6 to 0.4 & 0.66 \\
\hline Noradrenaline & $2 \cdot 5(0 \cdot 2)$ & $2 \cdot 6(0 \cdot 2)$ & -0.6 to 0.3 & 0.61 \\
\hline Growth hormone & $3.0(0.2)$ & $2.9(0.2)$ & -0.6 to 0.6 & 0.71 \\
\hline Subjective awareness & $2.5(0.1)$ & $2.5(0 \cdot 1)$ & -0.3 to 0.3 & 0.89 \\
\hline Adrenergic symptoms & $2 \cdot 7(0 \cdot 2)$ & $2 \cdot 7(0.2)$ & -0.4 to 0.5 & 0.79 \\
\hline Neuroglycopenic symptoms & $2 \cdot 8(0 \cdot 2)$ & $3 \cdot 0(0 \cdot 2)$ & -0.6 to 0.3 & 0.57 \\
\hline
\end{tabular}

$\star$ Paired $t$ test.
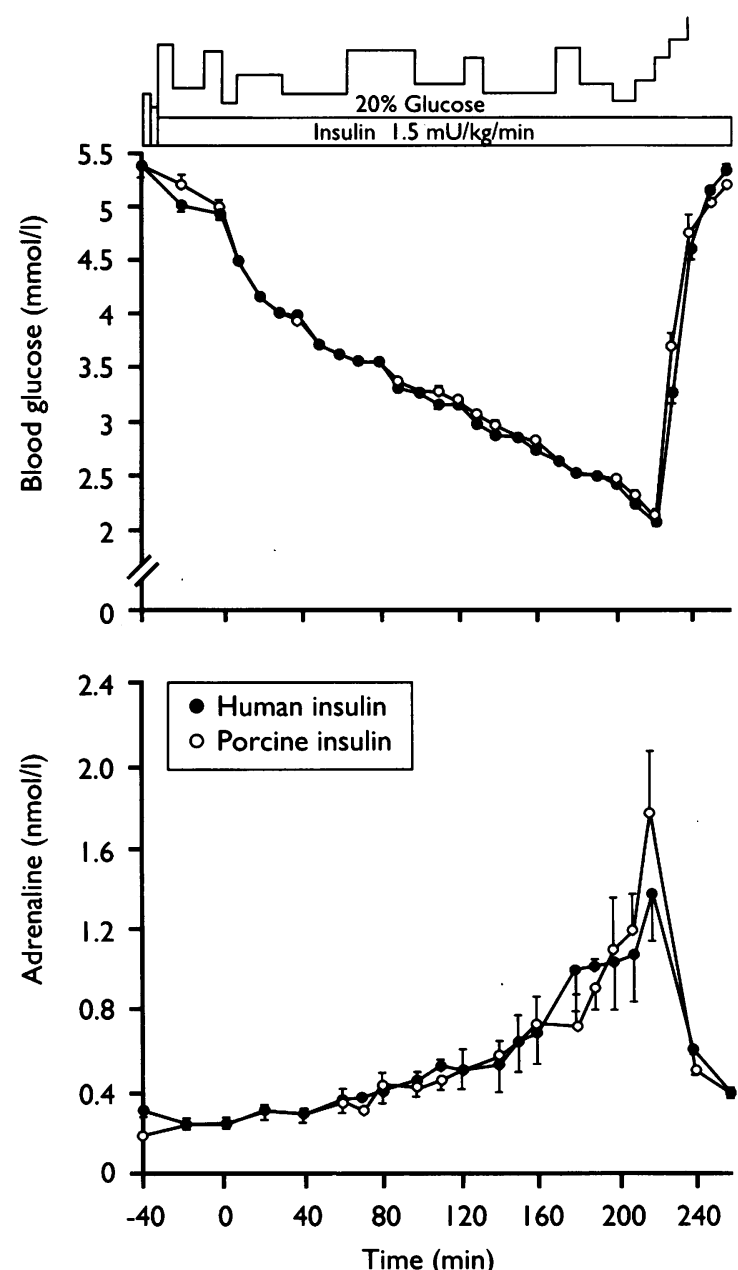

FIG 1-(Top) Mean blood glucose concentrations during slow fall hypoglycaemic clamps with human ( $(\bullet)$ and porcine (0) insulin. Bars represent $S E$ for group. Lines at top of diagram are schematic representation of infused insulin and glucose. (Bottom) Adrenaline responses to hypoglycaemic stimuli shown in upper panel

\section{CLAMP STUDIES}

The steady state plasma concentration of free insulin during the clamps was 67 (9) $\mathrm{mU} / \mathrm{l}$ with human insulin and $62(5) \mathrm{mU} / \mathrm{l}$ with porcine insulin $(\mathrm{p}=0.56)$. There were no significant differences between the blood glucose profiles in the two studies (fig 1 (top)). The adrenaline responses (fig 1 (bottom)) were similar for the two insulins (area under the curve $138(25) \mathrm{nmol} / \mathrm{/} /$ $240 \mathrm{~min}$ (human) $v 138(21) \mathrm{nmol} / \mathrm{l} / 240 \mathrm{~min}$ (porcine); $95 \%$ confidence interval -51 to $51 ; \mathrm{p}=0.9)$. The glucose concentration at which the adrenaline rose significantly was $3.0(0.2) \mathrm{mmol} / \mathrm{l}$ (human) v $3.1(0 \cdot 2)$ $\mathrm{mmol} / 1$ (porcine); $95 \%$ confidence interval -0.6 to $0 \cdot 4, p=0 \cdot 66)$. There were no significant differences between the two insulins in responses or glucose thresholds for release of the other counterregulatory hormones (table II).

Subjective awareness (a positive answer to the question "Do you feel low?") occurred at a lower blood glucose concentration than the initial adrenaline response but the threshold was identical for the two insulins $(2.5(0.1) \mathrm{mmol} / \mathrm{l})$. There were no significant differences in the glucose thresholds for a two point increase in symptom scores (table II). Median (range) symptom scores at the lowest glucose concentration were similar for the two insulins (total score: human $8(0-21) v$ porcine $6(0-31)$ (95\% confidence interval -4 to $3, Z=0.54, \mathrm{p}=0.59)$; autonomic score: $3(0-9) v$ $3(0-10),(-2$ to $2, Z=-0 \cdot 25, \mathrm{p}=0.79)$; and neuroglycopenic score: $2(0-16)$ v $5(0-21),(-3.5$ to 2 , $Z=-0 \cdot 47, \mathrm{p}=0 \cdot 63)$ ).

Performance on the four choice reaction time deteriorated with hypoglycaemia and improved again 
as euglycaemia was restored with both insulins. The glucose concentration at which noticeable slowing first occurred was $2.8(0.2)$ for human insulin and $2 \cdot 7(0 \cdot 1) \mathrm{mmol} / 1$ for porcine insulin $(95 \%$ confidence interval -0.3 to $0 \cdot 2 ; p=0.58)$. Loss of accuracy was demonstrable at a blood glucose concentration of $2 \cdot 7$ $(0 \cdot 2) \mathrm{mmol} / \mathrm{l}$ with human insulin and $2 \cdot 6(0 \cdot 1) \mathrm{mmol} / \mathrm{l}$ with porcine insulin $(-0.3$ to $0.5, p=0.52)$. A trend towards earlier deterioration in performance with porcine insulin (fig 2) was not significant.
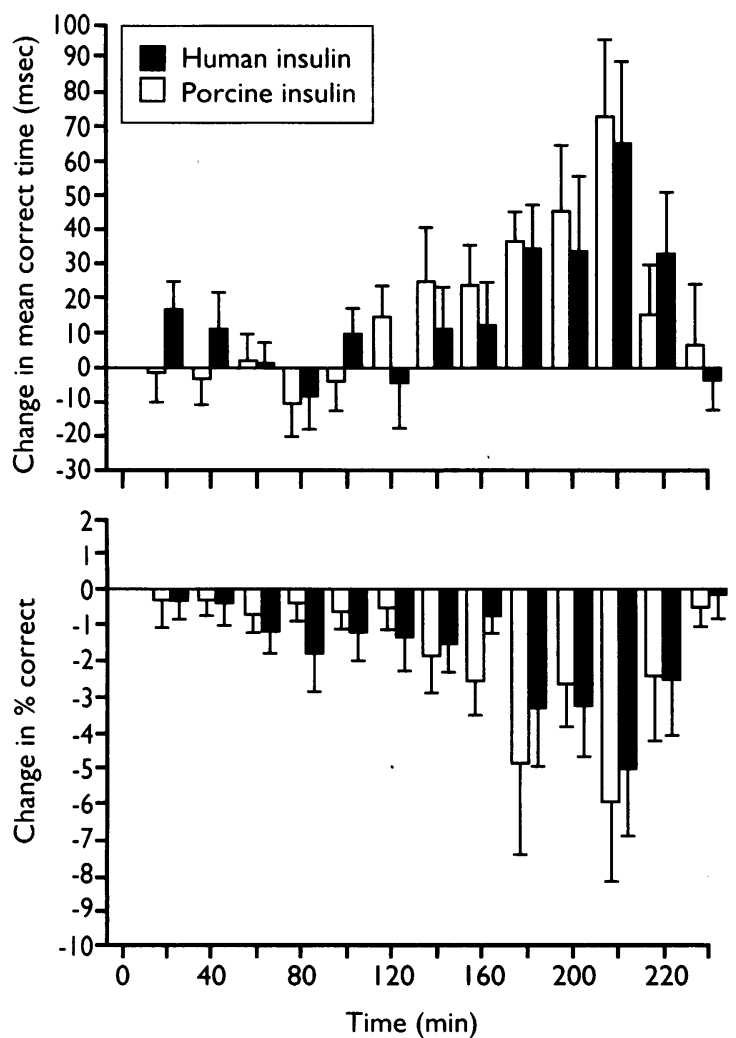

FIG 2-Change in time to make a correct response and decrease in \% of correct responses in five minutes on four choice reaction test during hypoglycaemic clamps with porcine and human insulin. Bars represent $S E$

\section{Discussion}

The possibility that transferring to human insulin adversely affects the incidence and presentation of hypoglycaemia has been extensively aired in the lay press and has given rise to much public concern. Legal action has been threatened. Clinic surveys in Scotland, ${ }^{4}$ America, ${ }^{5}$ and Germany $^{6}$ have failed to confirm an association but have been criticised for flaws in study design. ${ }^{35}$ There have been few controlled prospective studies of the effect of transferring to human insulin on the clinical presentation of hypoglycaemia. We found no change in the frequency of mild or severe hypoglycaemia during random double blind conversion to human insulin without change in glycaemic control which suggests that no causal relation exists.

It is unlikely that the (insignificantly) lower incidence of hypoglycaemia with human insulin in our study was due to loss of awareness and therefore reduced detection of hypoglycaemia because the incidence of severe and biochemical hypoglycaemic episodes did not differ for the two insulin species on routine monitoring. Attempts to avoid altered glycaemic control, which is a confounding variable, during the study might have masked a tendency for increased hypoglycaemia with human insulin, but since insulin doses did not change throughout the study this is also unlikely. A type 2 statistical error is possible in a clinical study of
17 patients, but our observations were very precise and carefully validated and agree with the results of a recent much larger study from Australia. ${ }^{36}$ Our data therefore do not support the hypothesis that transferring to human insulin by itself alters the frequency or experience of hypoglycaemia.

\section{CLAMP STUDIES}

During formal testing we found no differences in the hormonal responses to hypoglycaemia or the subjective awareness or type of symptoms experienced during hypoglycaemia with the two human species. Neither the size of the responses nor the glucose concentration at which they began during stepped slow fall hypoglycaemia was different. These findings agree with those of several published studies ${ }^{23-28}$ that did not precede the clamp study with two months' treatment with the study insulin as we did.

Responses to hypoglycaemia in a laboratory setting have been reported to be different in patients taking human and animal insulin. But many of the studies have been on non-diabetic subjects ${ }^{17-22}$ and the hypoglycaemic stimulus was not always identical. One study found an earlier increase in latency of the P300 wave (an electrophysiological measurement thought to relate to cortical function) during controlled hypoglycaemia with porcine insulin..$^{22}$ The authors suggested that the earlier (albeit transient) change in cerebral function with porcine insulin might be responsible for earlier triggering of counterregulatory and symptomatic responses to hypoglycaemia. We found a small tendency for an earlier deterioration in cognitive function, with loss of speed and accuracy of the four choice reaction during the controlled hypoglycaemia induced by porcine insulin but this did not achieve significance. The lack of difference in either hormonal or symptomatic responses suggests that an earlier change in cerebral function with porcine insulin is not associated with earlier warning during hypoglycaemia and may be deleterious.

Responses to controlled hypoglycaemia induced in a laboratory setting cannot be directly applied to the clinical situation. However, there is good precedent for using such methods to investigate the mechanisms underlying altered responsiveness and particularly loss of awareness of hypoglycaemia. Controlled experimental hypoglycaemia induced by a clamp technique similar to that which we used clearly showed delayed and diminished hormonal and symptomatic responses to hypoglycaemia in diabetic patients receiving intensified insulin therapy ${ }^{15}$-a situation in which loss of awareness of hypoglycaemia ${ }^{37}$ and increased risk of severe hypoglycaemia ${ }^{38}$ is well described. Similarly, laboratory testing has identified defective counterregulation in other patients with hypoglycaemia unawareness..$^{121316}$ The advantages of such testing include its precision with relatively small numbers of subjects. Furthermore, the guarantee of identical hypoglycaemic stimuli in all circumstances allows direct comparison of the results.

\section{CONCLUSIONS}

This study was designed to investigate the possibility that transferring to human insulin has a direct effect on the perception and experience of hypoglycaemia. It cannot rule out a difference in the pharmacokinetics of insulins from different species. The evidence suggests that human insulin is a faster and shorter acting insulin $^{3940}$ and caution should be exercised in transferring patients from animal insulins. Overnight control can be difficult with intermediate acting human insulins. ${ }^{\text {"0 }}$ Even so, we would expect that any systematic difference between the two insulins which was causally associated with loss of awareness of hypoglycaemia would have been detected in our study design. 
Our subjects had experienced a change in their hypoglycaemic experience, which they had attributed to their use of human insulin, although most of them were still using it. An irreversible alteration of hypoglycaemia response might have occurred, but this would not be compatible with reports of reversal of hypoglycaemia unawareness on return to animal insulin.

If human insulin does not cause a problem with hypoglycaemia awareness, what does? Most of our subjects had long duration disease and their diabetes was tightly controlled-both factors known to interfere with hypoglycaemia awareness. ${ }^{4738}$ This is also true of the patients in the Swiss clinic where doctors continue to describe problems with recognition of hypoglycaemia. ${ }^{111}$ The lack of change in metabolic control during our study may explain the stability of the hypoglycaemic experience of our subjects throughout. It remains possible that a few patients are susceptible to a change in insulin species, and obviously patients who are unhappy with human insulin should not remain on it. But our results argue against any systematic adverse effect of human insulin.

We thank the Juvenile Diabetes Foundation International and Novo-Nordisk, Copenhagen, Denmark and the special trustees of Guy's Hospital for supporting this research. We also thank Lucie Brunton for her secretarial and administrative support, Helen Simpson, Julie Taylor, and Gary Chusney for the laboratory assays, and Paul Chester.

1 Teuscher A, Berger WG. Hypoglycaemia unawareness in diabetics transferred from beef/porcine to human insulin. Lancet 1987;ii:382-5.

2 Berger WG, Althaus BV. Reduced awareness of hypoglycaemia after changing from porcine to human insulin in IDDM. Diabetes Care 1987;10:260-1

3 Berger M, Keller K, Honegger B, Jaeggi E. Warning symptoms of hypoglycaemia during treatment with human and porcine insulin in diabetes mellitus. Lancet 1989;i:1041-4.

4 Hepburn DA, Eadington DW, Patrick AW, Colledge NR, Frier BM Symptomatic awareness of hypoglycaemia: does it change on transfer to human insulin? Diabetic Med 1989;6:586-90.

5 Orchard TJ, Maser RE, Becker DJ, Dormans JS, Drash AL. Human insulin use and hypoglycaemia: insights from the Pittsburgh epidemiology of diabetes complications study Diabetic Med 1991;9:469-74.

6 Mulhauser I, Heinemann L, Fritsche E, von Lennep K, Berger M. Hypoglycemic symptoms and frequency of severe hypoglycemia in patients glycemic symptoms and frequency of severe hypoglycemia in patients
treated with human and animal insulin preparations. Diabetes Care treated with hum

7 Heine R, Van der Veen EA. Human insulin and hypoglycaemia. Lances 1990;355:62

8 Laron Z, Feinmesser P, Albag Y, Ofan R, Karp M. Hypoglycaemia in newly diagnosed diabetic children and adolescents-comparison between human and porcine insulin. Diabetologia 1988;31:45

9 Stephenson J, Fuller J. Hypoglycaemia as cause of death in the human insulin era. Lancet 1990;335:661.

10 Egger M, Davey Smith G, Imhoof H, Teuscher A. Risk of severe hypoglycaemia in insulin treated diabetic patients transferred to human insulin: a case-control study. BMF 1991;303:617-21.

11 Egger M,. Davey Smith G, Teuscher AU, Teuscher A. Influence of human insulin on symptoms and awareness of hypoglycaemia: a randomised double blind crossover trial. $B M 71991 ; 303: 622-6$.

12 Clausen Sjobom N, Adamson U, Lins PE. The prevalence of impaired glucose counterregulation during an insulin infusion test in insulin treated diabetic counterregulation during an insulin infusion test in insulin treated

13 Ryder REJ, Owens DR, Hayes TM, Ghatei MA, Bloom SR. Unawareness of hypoglycaemia and inadequate counterregulation: no causal relation with diabetic autonomic neuropathy. BMf 1990;301:783-7.

14 Amiel SA, Tamborlane WV, Simonson DC, Sherwin RS. Defective counter- regulation after strict glycemic control of insulin dependent diabetes mellitus. $N$ Engl f Med 1986;316:1376-83.

15 Amiel SA, Sherwin RS, Simonson DC, Tamborlane WV. Effect of intensified insulin therapy on glycemic thresholds for counterregulatory hormone release. Diabetes Care 1988;37:901-7.

16 Clarke WL, Gonder-Frederick LA, Richards FE, Cryer PE. Multifactorial origin of hypoglycemic symptom unawareness in IDDM. Diabetes 1991;40:680-5.

17 Heine RJ, Van der Heyden EAP, Van der Veen EA. Responses to human and porcine insulin in healthy subjects. Lancet 1989;ii:946-8.

18 Schluter KJ, Petersen KG, Sontheimer J, Enzmann F, Kerp L. Different counterregulatory responses to human insulin (recombinant DNA) and purified pork insulin. Diabetes Care 1982;5(suppl 2):78-81.

19 Rosak C, Althoff PH, Enzmann F, Schoffling K. Comparative studies on intermediary metabolism and hormonal counterregulation following human insulin (recombinant DNA) and purified pork insulin in man. Diabetes Care insulin (recombinant

20 Petersen KG, Schluter KJ, Kerp L. Less pronounced changes in serum potassium and epinephrine during hypoglycaemia induced by human insulin (recombinant DNA). Diabetes Care 1982;5:90-2.

21 Owens DR, Vora JP, Tronier B, Keller U, Luzio S, Turkes A. Hormonal counterregulatory responses to human (semi-synthetic and recombinan DNA) and porcine insulin induced hypoglycaemia. Diabetes Res 1988;8:1-8.

22 Kern WV, Lieb K, Kerner W, Born J, Fehm HL. Differential effects of human and porcine insulin induced hypoglycemia on neuronal function in humans. Diabetes 1990;39:1091-8.

23 Perez Fernandez R, Casaneuva FF, Devesa J, Cabezas Cerrato J. Metabolic and hormonal parameters after insulin hypoglycemia in man, comparison between biosynthetic human insulin and purified pork insulin. Horm Metab Res 1985;17:351-4.

24 Jones TW, Caprio S, Diamond MP, Hallarman L, Boulware S, Sherwin RS, Tamborlane WV. Does insulin species modify counterregulatory hormone Tamborlane WV. Does insulin species modify counterre

25 Bendtson I, Binder C. Counterregulatory hormone responses to insulininduced hypoglycaemia in IDD patients. A comparison of equimolar amounts of porcine and semisynthetic human insulin. $f$ Intern Med 1991;229:293-6.

26 Clausen Sjorborn N, Lins PE, Adamson V, Theodorsson E. A comparative study of the hormonal responses to insulin-induced hypoglycaemia using semi-synthetic and pork insulin in patients with insulin dependent diabete mellitus. Diabetic Med 1990;7:775-9.

27 Fisher BM, Gray CE, Beastall GH, Frier BM. Responses to acute insulininduced hypoglycaemia in diabetic patients: a comparison of short actin human and porcine insulins. Diabetes Res 1988;8:1-8.

28 Patrick AW, Bodmer CW, Tieszen KL, White MC, Williams G. Human insulin and awareness of acute hypoglycaemic symptoms in insulindependent diabetes. Lancet 1991;338:528-32.

29 Egger M, Davey Smith G, Teuscher A. Hypoglycaemia unawareness and human insulin. Lancet 1991;338:950.

30 Amiel SA, Simonson DC, DeFronzo RA, Tamborlane WV, Sherwin RS. The rate of glucose fall does not affect the counterregulatory hormone response to hypoglycemia in normal and diabetic man. Diabetes 1987;36:518-22.

31 Liu D, Moberg E, Kollind K, Lins P-E, Macdonald IA. Arterial, arterialized venous and venous and capillary blood glucose measurements in normal man during hyperinsulinaemic euglycaemia and hypoglycaemia. Diabetologia 1992;35:287-90.

32 Hepburn DA, Dery IJ, Frier BM, Patrick AW, Quinn JD, Fisher M, et al. Symptoms of acute insulin-induced hypoglycemia in humans with and without IDDM. Factor-analysis based approach. Diabetes Care 1991;14:949-57.

33 Kerr D, Macdonald IA, Tattersall RB. Patients with type 1 diabetes adapt acutely to sustained mild hypoglycaemia. Diabetic Med 1991;8:123-8.

34 Amiel SA, Pottinger R, Cunnah DC, Archibald HR, Chusney G, Prior P, et al. Effect of antecedent glucose control on cerebral function during hypoglycemia. Diabetes Care 1991;14:109-18.

35 Egger M, Smith GD, Diem P, Teuscher A. Human vs porcine insulin gone wrong. Diabetes Care 1992;15:585-6.

36 Colagiuri S, Miller J, Petocz P. Double-blind cross-over comparison of human and porcine insulins in patients reporting lack of hypoglycaemia awareness. Lancet 1992;339:1432-5.

37 The DCCT Research Group. Epidemiology of severe hypoglycemia in the diabetes control and complications trial. Am J Med 1991;90:450-9.

38 Lager I, Atvall S, Blohme G, Smith U. Altered recognition of hypoglycaemic symptoms in type 1 diabetes mellitus during intensified control with continuous subcutaneous insulin infusion. Diabetic Med 1986;3:322-5.

39 Ebihara A, Kondo K, Ohashi K, Kosaka K, Kuzuka T, Matsuda A Comparative clinical pharmacology of human insulin (Novo) and porcine insulin in human subjects. Diabetes Care 1983;6(suppl 1):17-22.

40 Home PD, Mann NP, Hutchison AS, Park R, Walford S, Murphy M, et al. A fifteen month double blind cross over study of the efficacy and antigenicity of human and pork insulins. Diabetes Med 1984;1:93-8.

(Accepted 30 October 1992)
Dog Flesh as aN ARTICle of Diet-An official document recently published by the municipal authorities of Munich gives some startling information as to the increased consumption in that city of dog flesh, an article of diet which has hitherto found most favour in the eyes of inhabitants of the Celestial Empire. So great an appetite do the denizens of the Bavarian capital seem to have developed for that "strange food" that the authorities have thought it time to interfere for the protection of dog owners, whose pets are stolen to grace the table of the intrepid gourmets who lust after these canine flesh pots. This new form of poaching has, it appears, grown into a regular industry in Munich, the demand creating the supply in accordance with economic laws. Dog flesh is largely consumed as such by Italian workmen, many thousands of whom are employed in Munich, but there is also much reason to believe that the same substance is as freely used in the concoction of sausages in that city as the flesh of the harmless necessary cat is supposed to be nearer home. (BMF 1893;i:47.) 